\title{
Utilização de enxerto cutâneo no tratamento de ferida traumática grave associada à luxação metatarsofalangeana aberta: relato de caso*
}

\section{Use of cutaneous graft in the treatment of severe traumatic cutaneous wound associated with open metatarsal and falloid dislocation: case report in dogs}

\author{
Leonardo Martins Leal, ${ }^{* *}$ Guilherme Mantuani Silva, ${ }^{* * *}$ Alan Moreno dos Santos, ${ }^{* * *}$ Carla Nazaré Magalhães, ${ }^{* * *}$ \\ Fabio Rodrigo Castro Bastos, ${ }^{* * *}$ Hélio Alberto Cumani Garcia, ${ }^{* * *}$ Josenéia Boeing, ${ }^{* * *}$ \\ Ícaro do Nascimento Argentino, ${ }^{* * *}$ Thamara Pazetto Fuzari ${ }^{* * *}$
}

\begin{abstract}
Resumo
Na pele, quando a cicatrização por primeira intenção não é possível devido ao excesso de tensão tecidual, a melhor opção se torna a utilização de técnicas cirúrgicas reconstrutivas como retalhos e enxertos. A utilização de enxertos ou retalhos, reduz consideravelmente o tempo de cicatrização das lesões, além de minimizar os riscos de possíveis infecções. Ademais, pela grande frequência de lesões traumáticas múltiplas, cutâneas e ósseas que ocorrem nos pequenos animais após atropelamentos e suas inúmeras opções de tratamento, o que torna por vezes difícil a escolha da melhor conduta a estes pacientes, objetivou-se descrever o tratamento de uma ferida traumática, utilizando, açúcar, tala de Robert Jones modificada, seguido de enxerto cutâneo em malha de espessura total, em um cão que apresentava extensa ferida cutânea infectada e luxação aberta metatarsofalangeana, dando ênfase ao retorno funcional do membro. O paciente canino, foi submetido ao tratamento por segunda intenção da ferida, até a mesma estar apta a receber a enxertia cutânea. Os resultados foram satisfatórios, ocorrendo cicatrização completa da ferida e reestabilização funcional do membro com 120 dias de tratamento. Conclui-se que a combinação de tratamentos, conservativo e cirúrgico, pode ser uma alternativa eficiente a amputação do membro no tratamento de ferida lacerada infectada associada a luxação articular completa, gerando resultados funcionais e estéticos satisfatórios.
\end{abstract}

Palavras-chave: cirurgia reconstrutiva, ortopedia, pequenos animais.

\begin{abstract}
In the skin, when healing by first intention is not possible due to excess tissue tension, the best option becomes the use of reconstructive surgical techniques such as flaps and grafts. The use of grafts or flaps, greatly reduces the healing time of the lesions, in addition to minimizing the risks of possible infections. In addition, due to the great frequency of multiple traumatic, cutaneous and bone injuries that occur in small animals after running over and their innumerable treatment options, which makes it sometimes difficult to choose the best behavior for these patients, the objective was to describe the treatment of a traumatic wound, using modified Robert Jones' sugar, followed by total thickness mesh cutaneous graft, in a dog that had an extensive infected cutaneous wound and open metatarsophalangeal luxation, emphasizing the functional return of the limb. The canine patient, was submitted to the second intention treatment of the wound until it was able to receive cutaneous grafting. The results were satisfactory, with complete wound healing and functional limb reestablishment with 120 days of treatment. It is concluded that the combination of conservative and surgical treatments can be an efficient alternative to limb amputation in the treatment of infected lacerated wound associated with complete joint dislocation, generating satisfactory functional and aesthetic results.
\end{abstract}

Keywords: reconstructive surgery, orthopedy, small animals.

\section{Introdução}

A pele é o maior órgão dos vertebrados e atua como uma barreira seletiva na superfície corpórea, que garante o equilíbrio fisiológico. A perda de sua integridade pode acarretar o surgimento de alterações substanciais deletérias e possíveis infecções podendo se agravar levando até mesmo ao óbito (THEORET, 2009).

Um ferimento é caracterizado como a interrupção da integridade anatômica, fisiológica e funcional dos tecidos corporais. Após uma lesão tecidual, o processo de cicatrização se inicia imediatamente através de eventos químicos, físicos e biológicos

*Recebido em 30 de outubro de 2018 e aceito em 26 de dezembro de 2018.

**Professor Adjunto, Centro Universitário Ingá - UNINGÁ; Medicina Veterinária, Maringá, Paraná, Brasil.

Autor para correspondência: leonardo.vet@hotmail.com

***Graduando, Centro Universitário Ingá - UNINGÁ; Medicina Veterinária, Maringá, Paraná, Brasil. 
que promovem a reparação do tecido lesionado (GREGORY, 1999; MACPHAIL, 2015).

O tratamento de feridas inclui a cicatrização por primeira intenção, segunda intenção ou terceira intenção, a decisão de escolha de um dos tratamentos se dá pela avaliação minuciosa de alguns aspectos básicos: mecanismo de lesão, existência de efracção (PAVLETIC, 2010), grau de lesão tecidual (TAZIMA et al. 2008), grau de contaminação (FORD, MAZZARERRO 2007), cor do tecido lesionado, características regionais da ferida e estado fisiológico geral do paciente (MACPHAIL, 2015).

Na pele, quando a cicatrização por primeira intenção não é possível devido ao excesso de tensão tecidual (PAVLETIC, 2010), a melhor opção se torna a utilização de técnicas cirúrgicas reconstrutivas como retalhos e enxertos (MACPHAIL, 2015; PROOT et al., 2018), especialmente em casos de lesões nos membros, que devido ao processo de contração da ferida, pode ocasionar limitações articulares. Ademais, a contração exagerada pode atuar como um torniquete natural, podendo levar a distúrbios hemodinâmicos da região distal do membro e ocasionar dor e constante formação de edema (HANKS; SPODNIK, 2005; ZINGEL; SAKALS, 2017).

A utilização de enxertos ou retalhos, reduz consideravelmente o tempo de cicatrização das lesões, além de minimizar os riscos de possíveis infecções (MACPHAIL, 2015). No momento de decidir a técnica a ser utilizada no procedimento cirúrgico, deve-se levar em consideração vários fatores, entre eles: a localização anatômica da ferida, qualidade do leito, elasticidade do tecido periférico, posicionamento ideal do enxerto ou retalho, suprimento sanguíneo local, tensão tecidual, padrão de sutura, fio a ser utilizado e cuidados pós-operatórios do paciente (PAVLETIC, 2010; MACPHAIL, 2015).

A maioria das fraturas e lesões em membros são ocasionadas por processos traumáticos resultantes de acidentes automobilísticos. Sendo assim, os membros se tornam susceptíveis a subluxação ou luxação completa das articulações em decorrência de trauma (HALL, 2011; RAMIREZ, 2016). No caso de luxação metacarpofalangeanas, metatarsofalageanas ou falangeanas, Davidson; Sharon; Millis (2006) citam como uma das alternativas a utilização de tala, buscando o reparo dos ligamentos colaterais e da cápsula articular.

Sendo assim, e pela grande frequência de lesões traumáticas múltiplas que ocorrem nos pequenos animais após atropelamentos e suas inúmeras opções de tratamento, incluindo a amputação do membro (MACPHAIL, 2015), o que torna por vezes difícil a escolha da melhor conduta a estes pacientes, objetivou-se relatar o caso de uma cadela com grave lesão traumática cutânea, muscular e óssea da região distal do membro pélvico esquerdo com luxação aberta metatársicafalangeana que teve excelente resposta ao tratamento preconizado com o uso de enxerto cutâneo e tala.

\section{Relato de caso}

Foi atendido na Clínica Veterinária Reino Animal, na cidade de Monte Azul Paulista-SP, um paciente canino, SRD, dois anos, 15 $\mathrm{kg}$, com extensa ferida cutânea e luxação metatarsofalangeana completa do membro pélvico esquerdo (Figuras 1 e 2). O tutor referiu que animal foi encontrado há 5 dias na rua após ter sido vítima de atropelamento automotivo. Foi realizado uma bandagem pelo próprio tutor no dia do ocorrido e nenhuma troca de bandagem ou limpeza da ferida foi realizada posteriormente.

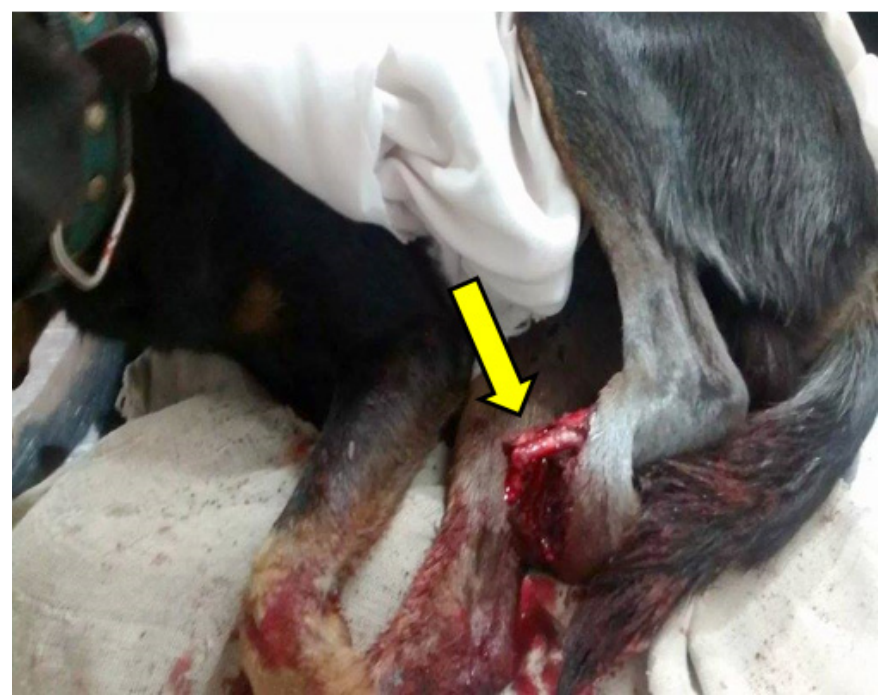

Figura 1: Imagem fotográfica do membro pélvico esquerdo de paciente canino. Observa-se extensa ferida cutânea e luxação metatarsofalangeana completa (seta). Vista lateral esquerda. Monte Azul Paulista-SP, 2015.

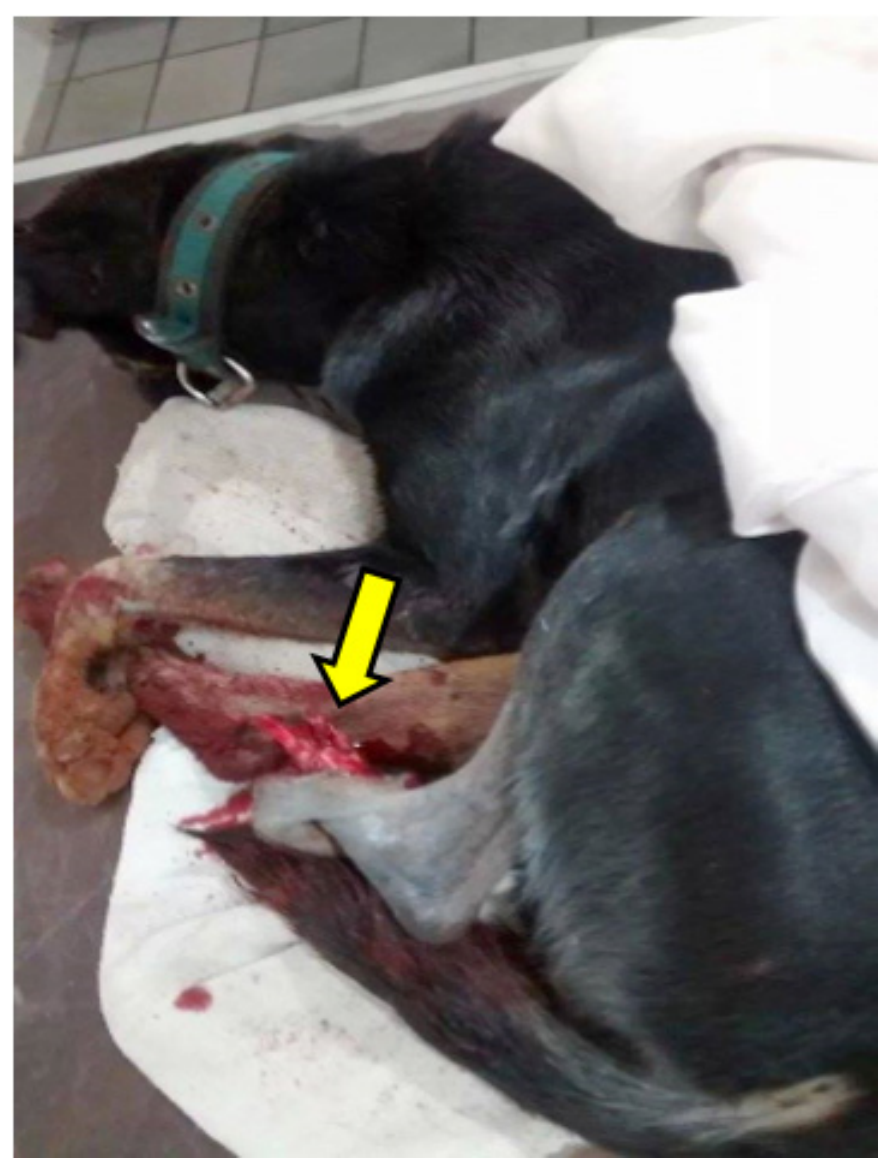

Figura 2: Imagem fotográfica do membro pélvico esquerdo de paciente canino. Observa-se extensa ferida cutânea e luxação metatarsofalangeana completa do membro pélvico esquerdo (seta). Vista caudal. Monte Azul Paulista-SP, 2015. 
Na avaliação clínica do paciente, pôde-se observar claramente a luxação completa da articulação metatarsofalangeana esquerda e uma extensa ferida cutânea com odor fétido acometendo grande parte da região metatársica medial esquerda. No centro da lesão, observaram-se áreas de necrose evidenciada pela coloração escurecida com regiões avasculares, além de fragmentos ósseos desvitalizados. Na avaliação neurológica, o paciente possuía sensibilidade a dor superficial e profunda do membro acometido. $\mathrm{O}$ mesmo apresentava outras escoriações cutâneas de menor gravidade por todo o corpo.

O paciente estava alerta e todos os parâmetros clínicos estavam dentro da normalidade. No hemograma, notou-se discreta leucocitose por neutrofilia com desvio a esquerda. No exame radiográfico observou-se luxação de todas as falanges do membro pélvico esquerdo.

Diante do quadro geral e avaliação minuciosa da lesão, optou-se pelo tratamento por segunda intenção da ferida até a mesma estar apta a receber um enxerto cutâneo. A ferida foi tratada diariamente com desbridagem dos tecidos desvitalizados, limpeza abundante com solução de ringer com lactato estéril e coberta com açúcar cristal; posteriormente, era confeccionada uma tala de Robert Jones modificada (com material rígido) para manter a imobilização da articulação metatarsofalangeana em posição anatômica. O responsável pelo animal foi orientado da possível necessidade de intervenção cirúrgica ortopédica futura para estabilização da articulação em caso de falha do tratamento conservador.

Além do tratamento tópico, foi prescrito o uso de Ranitidina $(2,2 \mathrm{mg} / \mathrm{kg}$, BID, 30 dias), Cefalexina (30mg/kg, BID, 30 dias), Tramadol (4mg/kg, TID, 10 dias) e Meloxicam $(0,1 \mathrm{mg} / \mathrm{kg}$, SID, 5 dias). Após 30 dias de tratamento, a ferida estava coberta por rico tecido de granulação (Figura 3), sem qualquer evidência de infecção. Deste modo, o paciente foi encaminhado para a cirurgia reconstrutiva do defeito cutâneo. Inicialmente utilizou-se de uma compressa estéril para demarcar a ferida do leito receptor e estimar o tamanho do retalho a ser retirado da área doadora (Figura $4 \mathrm{~A}$ ). A pele doadora foi retirada

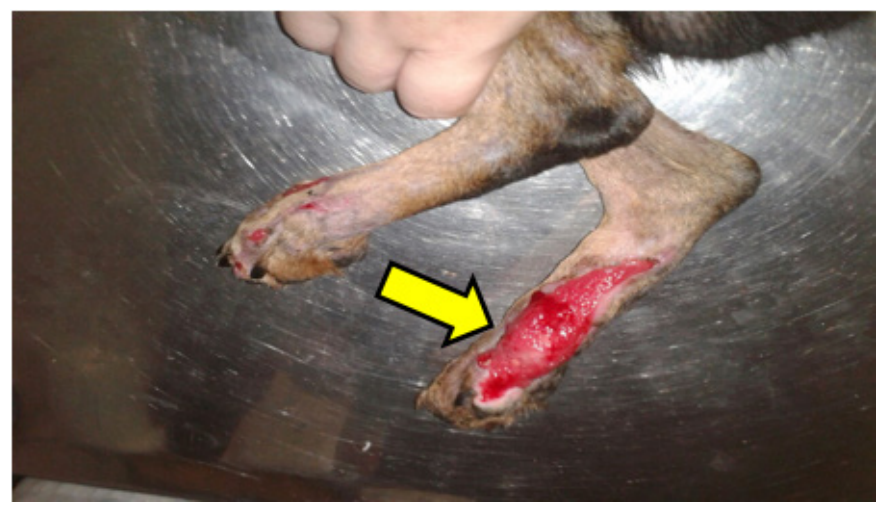

Figura 3: Aspecto macroscópico do leito receptor na região metatársica medial esquerda de paciente canino. Observa-se a ferida coberta por rico tecido de granulação (seta). Monte Azul Paulista-SP, 2015. do flanco (Figura 4B), retirou-se todo o tecido subcutâneo (Figura 4C) e realizou-se pequenas incisões sequenciais para formar uma malha com a pele (Figura 4D).

O leito receptor foi lavado, as bordas da ferida foram excisadas e o enxerto colocado sobre o tecido de granulação e suturado

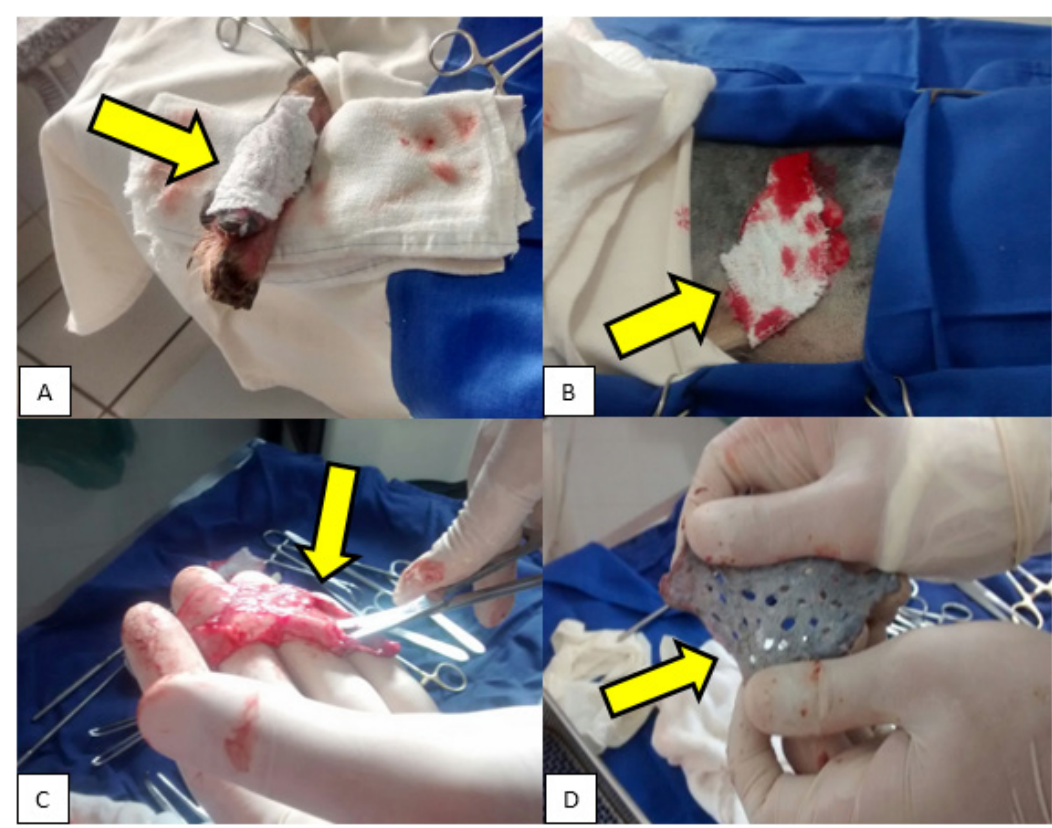

Figura 4: Imagens fotográficas transoperatórias de paciente canino. Observa-se a demarcação com compressa estéril do leito receptor (seta em A), para estimar o tamanho da pele a ser retirada da área doadora (seta em B). Retirada de todo o tecido adiposo e subcutâneo (seta em C); e posterior preparação do enxerto em malha (seta em D). Monte Azul Paulista-SP, 2015

nas bordas da ferida, utilizando-se fio de nylon número 3-0 e padrão de sutura simples interrompido (Figura 5A).

Após a cirurgia realizou-se a tala de Robert Jones modificada, a qual era trocada a cada 3 ou 4 dias até a completa cicatrização do enxerto. A cada troca de tala, a ferida era apenas lavada com solução de ringer lactato estéril, nenhum produto tópico foi utilizado. Foram prescritos Ranitidina $(2,2 \mathrm{mg} / \mathrm{kg}$, VO, BID, 10 dias), Cefalexina (30mg/kg, VO, BID, 10 dias), Metronidazol (20mg/kg, VO, BID, 5 dias), Tramadol (3mg/kg, VO, TID, 5 dias), Meloxicam (0,1 mg/kg, VO, SID, 3 dias) e recomendou-se o uso de colar elisabetano.

Após 7 dias da cirurgia, a borda do enxerto mostrava sinais de isquemia; todavia a região central estava potencialmente vitalizada (Figura 5B). Com 11 dias de pós-operatório, a borda da ferida sofreu deiscência de sutura. Com 15 dias, a região periférico enxerto, na qual houve deiscência da sutura, começou a ser preenchida por tecido de granulação. Com 30 dias após a cirurgia, o centro do enxerto estava aderido ao leito receptor e a borda em avançada fase de cicatrização (Figura 5C). Com 60 dias, a pele estava cicatrizada. Ao avaliar o paciente após 90 dias da cirurgia, o mesmo estava em boas condições clínicas, pelos começavam a crescer no enxerto (Figura 5D).

O animal apoiava o membro acometido sem qualquer evidencia de claudicação. Deste modo, mesmo com maior dorsoflexão das falanges (Figura 6), a cirurgia ortopédica foi dispensada e o paciente recebeu alta médica. 


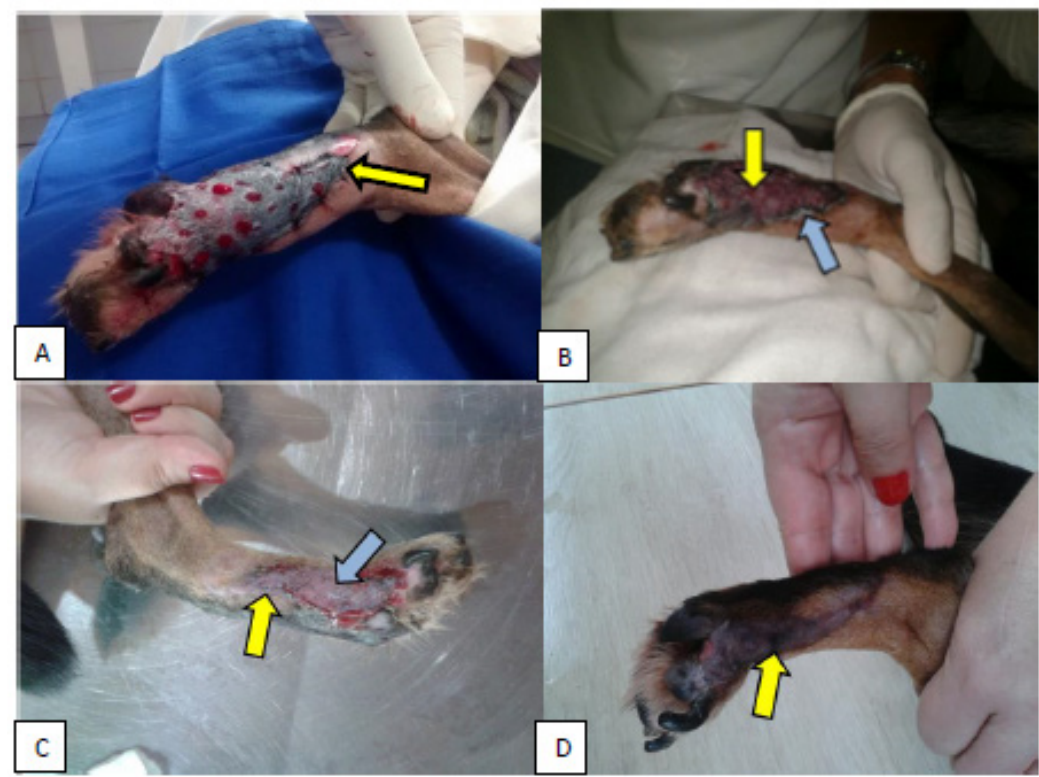

Figura 5: Imagens fotográficas pós-operatórias; aspecto macroscópico do leito receptor na região metatársica medial esquerda. Enxerto em malha suturado nas bordas da ferida (seta em A). Sinais de isquemia (seta azul em B); região central da lesão vitalizada (seta amarela em B). Centro do enxerto aderido ao leito receptor (seta azul em C) e borda em fase de cicatrização (seta amarela em C) e crescimento dos pelos sobre o enxerto (seta em D). Monte Azul Paulista-SP, 2015.

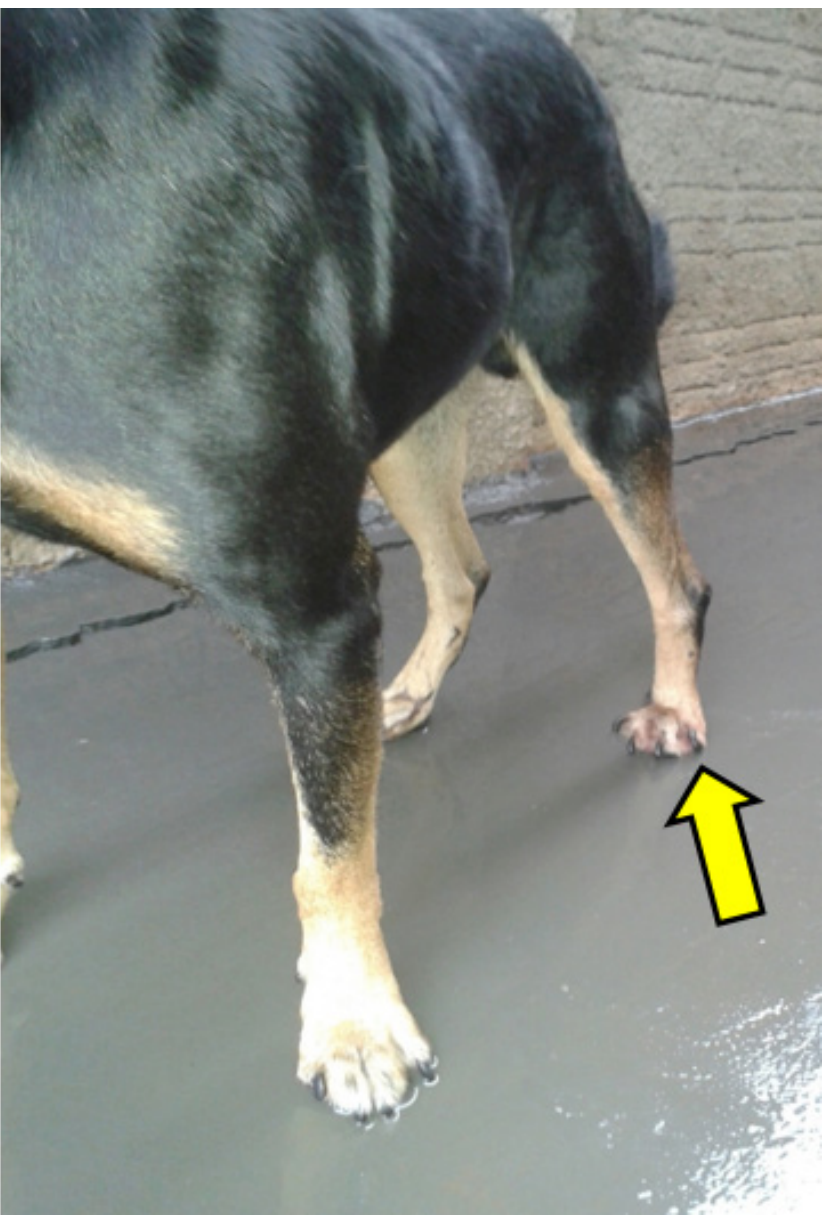

Figura 6: Imagem fotográfica pós-operatória do paciente canino apresentando dorsoflexão das falanges (seta). Monte Azul Paulista-SP, 2015.

\section{Discussão}

A maioria das fraturas ortopédicas, são ocasionadas por processos traumáticos resultantes de acidentes automobilísticos (KLATZKOW et al., 2018), enfatizando as circunstâncias resultantes do trauma no presente relato.

$\mathrm{Na}$ avaliação clínica do paciente, verificouse luxação aberta completa da articulação metatarsofalangeana esquerda, em decorrência do trauma (HALL, 2011). No exame neurológico, a presença de dor superficial no membro lesionado indicou a integridade dos neurónios aferentes e segmentos espinhais associados (KLATZKOW et al., 2018), por este fato optou-se pela preservação e tratamento do membro. Embora alguns autores indiquem a amputação do membro em casos de fraturas que possuem complicações não tratáveis (MACPHAIL, 2015), isso se torna confuso na prática veterinária; pois muitos médicos veterinários podem tomar decisões precipitadas, baseadas apenas no comprometimento cutâneo e muscular do membro.

Além da luxação, pôde-se observar na região metatársica medial esquerda, uma extensa ferida cutânea com áreas de coloração escurecida no centro da lesão; regiões avasculares; odor fétido e presença de fragmentos ósseos desvitalizados, caracterizando áreas de necrose tecidual (BARNES et al., 2018). Podendo então, classifica-la em uma ferida lacerada infectada, de acordo com o mecanismo de lesão e o grau de contaminação respectivamente (TAZIMA et al., 2008).

Após a avaliação minuciosa do paciente, a classificação da ferida de acordo com as características macroscópica previamente citadas, e a tentativa de preservação do membro, optou-se pelo emprego da cicatrização por segunda intenção, sendo o método mais indicado por Dernell (2006), devido ao tempo de contaminação da ferida, com mais de seis horas após o trauma, e alto risco de encarceramento bacteriano caso uma cirurgia reconstrutiva por primeira intenção fosse realizada de imediato.

A ferida foi tratada diariamente com desbridamento seletivo, a fim de retirar os tecidos necrosados (PAVLETIC, 2010) e estimular o início da fase proliferativa de cicatrização (LIPTAK, 1997). Após a limpeza abundante com solução de ringer com lactato estéril (LEAL; MARTINS, 2015), a ferida era coberta com açúcar cristal com a finalidade de inibir o crescimento de bactérias gram-negativas, gram-positivas, reduzir edema (KNUTSON et al., 1981), reduzir o teor de umidade da ferida e estimula a formação do tecido de granulação (PAVLETIC, 2010).

MacPhail (2015) recomenda a utilização de antibióticos tópico no tratamento de ferimentos abertos, porém os mesmos possuem um maior custo, risco de resistência bacteriana e intoxicação local, que nos direcionou a utilização do açúcar como método alternativo. Posteriormente, era confeccionada uma tala de Robert Jones modificada (com material rígido) para imobilizar a articulação metatarsofalangeana, tendo como objetivo, a cicatrização da região, mimetizando os ligamentos colaterais e a cápsula articular (DAVIDSON et al., 2006).

Após 30 dias de tratamento, a lesão possuía, tecido de granulação saudável e rica vascularização local sem presença 
de infecção (GREGORY, 1999; SLATTER, 2007; MACPHAIL, 2015; BARNES et al., 2018). Sendo assim, optou-se realizar a enxertia cutânea, indicada por Gregory (1999) e Macphail (2015) em casos de grandes defeitos em membros.

Nos membros, a excessiva contração da ferida pode acarretar limitações articulares e formar um torniquete natural, ocasionando alterações vasculares, dor e formação constante de edema (HANKS, SPODNIK, 2005). Diante desse fato, a utilização da enxertia cutânea no presente relato, teve como objetivo, diminuir o período de cicatrização da lesão (MACPHAIL, 2015; BARNES et al., 2018) e evitar as possíveis complicações previamente citadas. $O$ enxerto foi retirado da região do flanco, sendo uma área doadora que possui grande disponibilidade de pele, permitindo um fechamento da incisão cirúrgica sem tensão (SLATTER, 2007; MACPHAIL, 2015).

É sabido que enxertos em malha de espessura total possuem maior dificuldade de adaptação ao leito receptor quando comparado aos enxertos cutâneos que utilizam apenas a epiderme (CLODIUS, SMAHEL, 1971). Todavia, Macphail (2015) indica a utilização desta técnica de espessura total em malha em grandes defeitos de superfícies flexoras e extremidades distais. Deste modo, foi definido a utilização da técnica, devido a sua maior facilidade de coleta, boa capacidade de expansão e boa drenagem de fluido.

A tala de Robert Jones modificada foi utilizada no pós-operatório, com o intuito de promover a imobilização da articulação e facilitar a aderência do enxerto no leito receptor; ademais, evitou possíveis traumas e a contaminação da ferida (PAVLETIC, 2010; MACPHAIL, 2015). Pope (1998) relata que a troca de bandagem não deve ultrapassar 48 horas, porém o mesmo cita que a manipulação no momento da troca, aumenta o risco da ruptura do selo de fibrina entre o leito receptor e o enxerto. No pós-operatório, a tala foi trocada a cada três ou quatro dias, devido a indisponibilidade do proprietário de levar o animal a cada 48 horas. Todavia, isso não ocasionou complicações. O uso do colar elisabetano foi recomendado por todo o período em que o paciente esteve de tala para evitar arrancamento com a boca e umedecimento com saliva (SLATTER, 2007; MACPHAIL, 2015).

\section{Referências}

AGOSTINI, S.A.; SILVA; E.M; VARALLO, G. R. Princípios da enxertia cutânea em cães. Revista Científica de Medicina Veterinária-UNORP, v. 2, n. 1, p. 21-33, 2018.

BARNES, K. LANZ, O.; BARRY, S.; AULAKH, K. Use of cancellous bone grafting to promote granulation tissue in a distal limb wound in a dog. Journal of Small Animal Practice. 2018.

CLODIUS, L.; SMAHEL, J. The blood vessel system of free human skin grafts. Plastic and Reconstructive Surgery. v. 47, n. 1, p. 61-66, 1971.

DAVIDSON, J.R.; SHARON, C.K.; MILLIS, D.L. Reabilitação ortopédica. In: LEVINE, D. (ed) Reabilitação e Fisioterapia na prática de pequenos animais. São Paulo: Roca, 2006.

FORD, R.; MAZZAFERRO, E. Kirk y Bistner Urgencias en veterinária. Procedimientos y Terapéutica. Philadelphia: Saunders, 2007, 734p

HALL, K. Canine trauma: Literature review and evidence based medicine. Journal of veterinary emergency and critical care, v. 21, n. 5, p. 572-575, 2011.
Após sete dias da cirurgia, a região central do enxerto estava vitalizada e a borda apresentava sinais de isquemia, porém não se observou complicações como: seroma, edema, deiscência de sutura, infecção e necrose que são comumente reportadas por diversos autores (SLATTER, 2007; PAVLETIC, 2010; MACPHAIL, 2015; AGOSTINI et al., 2018). Com 11 dias de pós-operatório, a borda da ferida sofreu deiscência de sutura, complicação comum nestes casos devido a menor vascularização nas bordas da ferida. Todavia, a região central apresentava ótima viabilidade e coloração avermelhada, indicando sobrevivência do enxerto (SLATTER, 2007; PAVLETIC, 2010; MACPHAIL, 2014; AGOSTINI et al., 2018). Com 15 dias após a cirurgia, a região periférica do enxerto começou a ser preenchida por tecido de granulação, indicando a fase proliferativa do processo de cicatrização (PAVLETIC, 2010).

Com 30 dias após a cirurgia, o centro do enxerto estava aderido ao leito receptor e a borda em avançada fase de cicatrização, podendo observar a contração das bordas em direção ao tecido de granulação (PAVLETIC, 2010). Com 60 dias, a pele estava cicatrizada, observando total restauração do tecido epitelial (PAVLETIC, 2010). Com 90 dias o paciente apoiava o membro ao solo sem nenhuma restrição e pelos começavam a nascer no enxerto. Também aos 90 dias de pós-operatório, foi observado dorsoflexão das falanges quando o paciente apoiava o membro no solo, porém a realização de uma cirurgia ortopédica foi descartada, devido a ótima apresentação clínica do animal, sem qualquer sinal de claudicação do membro.

\section{Conclusão}

De acordo com os resultados obtidos durante o acompanhamento do presente caso clinico, conclui-se que a combinação de tratamentos conservativos (açúcar tópico; tala de Robert Jones modificada com material rígido) e cirúrgico posteriormente (enxerto em malha de espessura total), pode ser uma alternativa eficiente no tratamento de ferida lacerada infectada, associada a luxação completa da articulação metatarsofalangeana, gerando resultados funcionais e estéticos satisfatórios.

HANKS, J.; SPODNICK, G. Wound healing in veterirary rehabilitation patient. Veterirary Clinics of North America Small Animal Practice. v. 35, n. 6, p. 1453-1471, 2005.

KLATZKOW, S.; JOHNSON, M.D.; JAMES, M.; CARRERAJUSTIZ, S. Ventral Stabilization of a T2-T3 Vertebral Luxation via Median Sternotomy in a Dog. Case reports in veterinary medicine, v. 2018, 2018.

KNUTSON, R.A.; MERBITZ, L.A.; CREEKMORE, M.A.; SNIPES, H.G. Use of sugar and povidone-iodine to enhance wound healing: five years'experiense. Southern Medical Journal. v. 74, n. 11, p. 1329-1335, 1981.

LEAL, L.M.; MARTINS, A.R.C. Afecções cirúrgicas emergências em pequenos animais: guia prático para clinico de cães e gatos. 1. ed. São Paulo: MedVet, 2014, 158 p.

LIPTAK, J.M. Na overview of the topical management of wounds. Australian Veterinary Journal. v. 75, n. 6, p. 408-413, 1997.

MACPHAIL, C. Cirurgia do sistema tegumentar. In: FOSSUM, T. (ed.) Cirurgia de pequenos animais. Rio de Janeiro: Elsevier, 2015, p. 190-288. 
PAVLETIC, M. Atlas of small animal wound management and reconstructive surgery. 3 ed. Cambridge: Wiley-Blackwell, 2010 , $880 \mathrm{p}$.

PROOT, J.L.J.; JEFFERY, N. CULP, W.T.N.; BURACCO, P.; DE LA PUERTA, B.; WILLIAMS, J. M.; POPE, J. F. A. Is the caudal auricular axial pattern flap robust? A multi-centre cohort study of 16 dogs and 12 cats (2005 to 2016). Journal of Small Animal Practice, 2018.

RAMIREZ, J. M.; MACIAS, C. Pancarpal arthrodesis without rigid coaptation using the hybrid dynamic compression plate in dogs. Veterinary Surgery, v. 45, n. 3, p. 303-308, 2016.
SLATTER, D. Manual de Cirurgia de Pequenos Animais. 3 ed. São Paulo: Manole, 2007, 2830p.

TAZIMA, M.F.G.S.; VICENTE, Y.A.M.V.A.; MORIYA, T. Biologia da Ferida e Cicatrização. Fundamentos em clínica cirúrgica. Medicina, v. 41, n. 3, 2008.

THEORET, C. Tissue engineering in wound repair: the three "R"s - repair, replace, regenerate. Veterinary Surgery. v. 38, n. 8, p. 905-913, 2009.

ZINGEL, M.M.; SAKALS, S.A. Use of skin stretching techniques before bilateral caudal superficial epigastric axial flaps in a dog with severe burns. The Canadian Veterinary Journal, v. 58, n. 8, p. 835, 2017. 